Research Article

\title{
Vibration Analysis of a Two-Step Sine Movable Tooth Drive
}

\author{
Lizhong Xu $(\mathbb{D}$ and Jinan Yang \\ Mechanical Engineering Institute, Yanshan University, Qinhuangdao 066004, China \\ Correspondence should be addressed to Lizhong Xu; xlz@ysu.edu.cn
}

Received 3 May 2018; Accepted 26 September 2018; Published 24 October 2018

Academic Editor: Roger Serra

Copyright (C) 2018 Lizhong Xu and Jinan Yang. This is an open access article distributed under the Creative Commons Attribution License, which permits unrestricted use, distribution, and reproduction in any medium, provided the original work is properly cited.

In this study, a 3D model of a two-step sine movable tooth drive is developed in the UG software. The finite element model (FEM) analysis package, ANSYS, is used to calculate the natural frequencies and vibration modes of the drive system. The results show that the first twenty natural frequencies can be classified into five families, including the total system vibration mode, single-element vibration mode, two-element vibration mode, three-element vibration mode, and four-element vibration mode. The effects of the system parameters on the natural frequencies and the vibration modes are investigated. The track amplitude, the movable tooth radius, the radius of the movable tooth rotation, and the number of movable teeth affect the natural frequencies and vibration modes of the drive system.

\section{Introduction}

Gear drives are used widely in mechanical engineering. As engineering technology has progressed, a long life, small size, and light weight have become new requirements for gear drives. Movable tooth drives have the advantages of light weight, high transmission efficiency, wide range of transmission ratio, and large bearing capacity and they have been used in various fields including renewable energy, aerospace, national defense, precision instruments, oil, mining, and other industrial production. In the 1980s-1990s, much of research on movable tooth transmission was conducted in various countries. American scholars have put forward ball-bearing type gear drive system $[1,2]$. Japanese scholars studied the motion principles, strength design, curvature, pressure angle, and efficiency of cycloid ball reducers [3-6]. After 2000, more indepth studies on movable tooth drive system were conducted. In 2006, a failure analysis of a sine ball tooth drive was performed [7]. In 2009-2010, a two-stage cycloid ball reducer was proposed, and the profile calculation of the drive was completed $[8,9]$. In 2011, the tooth profile and strength of a swingmovable tooth drive was analyzed [10]. In 2012, a movable tooth drive was optimized and used in an electric drive system [11]. In 2013, a ball tooth thin-plate drive system was designed and used for operating robots [12]. In 2014, an eccentric movable tooth drive system was proposed and used for operating a robot arm [13]. In 2015-2016, an electromagnetic harmonic movable tooth drive system was proposed and the design reduced the integral size of the electromechanical drive system $[14,15]$.

In 2017, a two-step sine movable tooth drive was proposed in which the smallest radial size of the drive system was realized [16]. The two-step sine movable tooth drive is shown in Figure 1. It consists of five basic elements: (a) the central input shaft on which an outer sine ball track with period number $Z_{1}$ (here $Z_{1}=1$ ) is produced; (b) the shell on which two rows of the inner sine ball tracks with period number $Z_{3}$ and $Z_{4}$, respectively (here $Z_{3}=5$ and $Z_{4}=5$ ), are produced; (c) ten balls, movable teeth; (d) the first-step output shaft on which guide slots for movable teeth and an outer sine ball track with period number $Z_{2}$ (here $Z_{2}=1$ ) are produced; and (e) the second-step output shaft on which guide slots for movable teeth are produced.

When the input shaft rotates, the outer sine ball track meshes with the first row balls, which mesh with the first row of the inner sine ball track on the shell. When the shell is fixed, the balls drive the first-step output shaft by guide slots to initiate a rotation. The ball track on the first-step output shaft meshes with the second row of the balls that mesh with the second row of the inner sine ball track on the shell. As mentioned above, the shell is fixed so that the second output shaft is driven by the second row balls to rotate. If the input shaft rotates one circle, the output shaft rotates $Z_{1} Z_{2} /\left(Z_{1}+\right.$ $\left.Z_{3}\right) \cdot\left(Z_{1}+Z_{4}\right)$ circles. Thus, a much larger reduction speed ratio $i$ is given (here, $i=36$ ). This principle is especially suitable for oil drilling machines and robot arms. 


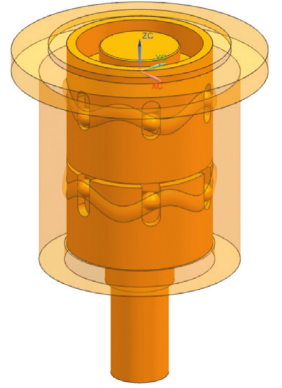

(a)

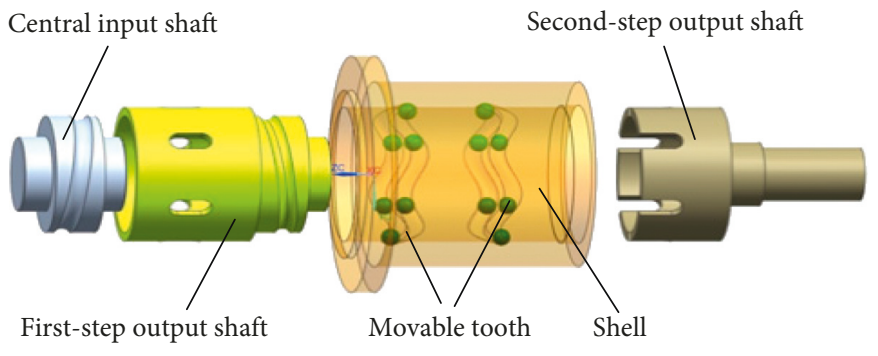

(b)

Figure 1: 3D model of the drive system. (a) 3D model; (b) installation of drive system.

However, an undesirable dynamic performance will result in noise and unacceptable performance characteristics of the drive system. The prediction of the natural frequencies and vibration modes is required in the design stage. The vibration performance of the two-step sine movable tooth drive requires further investigation.

In this study, 3D models of the main elements of the twostep sine movable tooth drive and the drive system are developed using the UG software package (a 3D drawing software). The finite element model (FEM) analysis package, ANSYS Workbench, is used to calculate natural frequencies and vibration modes of the drive system. The results show that the first twenty natural frequencies can be classified into five families that include total system vibration mode, singleelement vibration mode, two-element vibration mode, threeelement vibration mode, and four-element vibration mode. The effects of the system parameters on the natural frequencies and these vibration modes are investigated. These results provide guidance for the dynamic design of the drive system.

\section{3D Model of the Two-Step Sine Movable Tooth Drive}

The teeth of the central input shaft and shell are cut on the three-dimensional curves, so it is difficult to construct their $3 \mathrm{D}$ models. Their basis is calculation of the pattern curves.

In movable tooth coordinate system, the movable tooth can be calculated easily as follows:

$$
\vec{r}_{0}=r \cos v \vec{i}_{0}+r \cos u \sin v \vec{j}_{0}+r \sin u \sin v \vec{k}_{0},
$$

where $u$ and $v$ are the geometric parameters of the ball surface and $r$ is the movable tooth radius.

The surface of the movable tooth is transformed to the coordinate system of the central input shaft, and the tooth surface equation on the central input shaft can be given as

$$
\left\{\begin{array}{l}
x_{1}=r \cos v \cos \varphi_{1}-r \cos u \sin v \sin \varphi_{1}+R \cos \varphi_{1}, \\
y_{1}=r \cos v \sin \varphi_{1}+r \cos u \sin v \cos \varphi_{1}+R \sin \varphi_{1}, \\
z_{1}=r \sin u \sin v+A \sin \left(Z_{1} \varphi_{1}\right), \\
\tan u=\frac{-R}{A Z_{1} \cos \left(Z_{1} \varphi_{1}\right)},
\end{array}\right.
$$

where $\varphi_{1}$ is the angle between coordinate systems of the central input shaft and the first-step output shaft; $R$ is the rotational radius of the movable tooth center; $Z_{1}$ is the tooth number on the central input shaft; and $A$ is the sine amplitude.

Transforming the surface of the movable tooth to the first-step output shaft coordinate system, the tooth surface equations on the first-step output shaft are obtained:

$$
\left\{\begin{array}{l}
x_{2}=r \cos v \cos \varphi_{2}-r \cos u \sin v \sin \varphi_{2}+R \cos \varphi_{2}, \\
y_{2}=r \cos v \sin \varphi_{2}+r \cos u \sin v \cos \varphi_{2}+R \sin \varphi_{2}, \\
z_{2}=r \sin u \sin v+A \sin \left(Z_{2} \varphi_{2}\right), \\
\tan u=\frac{-R}{A Z_{2} \cos \left(Z_{2} \varphi_{2}\right)},
\end{array}\right.
$$

where $\varphi_{2}$ is the angle between the first- and second-step output shaft coordinate systems and $Z_{2}$ is the tooth number on the second-step output shaft.

In a same manner, the surface of the movable tooth can also be transformed to shell coordinate system to give the tooth surface equations on the shell as follows:

$$
\left\{\begin{array}{l}
x_{3}=r \cos v \cos \varphi_{3}+r \cos u \sin v \sin \varphi_{3}+R \cos \varphi_{3}, \\
y_{3}=-r \cos v \sin \varphi_{3}+r \cos u \sin v \cos \varphi_{3}-R \sin \varphi_{3}, \\
z_{3}=r \sin u \sin v+A \sin \left(Z_{3} \varphi_{3}\right), \\
\tan u=\frac{-R}{A Z_{3} \cos \left(Z_{3} \varphi_{3}\right)},
\end{array}\right.
$$

$$
\left\{\begin{array}{l}
x_{4}=r \cos v \cos \varphi_{4}+r \cos u \sin v \sin \varphi_{4}+R \cos \varphi_{4} \\
y_{4}=-r \cos v \sin \varphi_{4}+r \cos u \sin v \cos \varphi_{4}-R \sin \varphi_{4} \\
z_{4}=r \sin u \sin v+A \sin \left(Z_{4} \varphi_{4}\right) \\
\tan u=\frac{-R}{A Z_{4} \cos \left(Z_{4} \varphi_{4}\right)}
\end{array}\right.
$$

where Equations (4) and (5) give the equations of the first and second rows of the inner sine ball tracks on the shell, respectively. $\varphi_{3}$ and $\varphi_{4}$ are the angles between coordinate systems of the first and second row shell teeth to the firststep output shaft, respectively. $Z_{3}$ and $Z_{4}$ are the number of the first and the second row teeth on the shell, respectively. 
Based on above equations, in the environment of the UG software package, the 3D model of the drive system can be constructed. The main parameters of the drive system are given in Table 1. It is indicated as follows:

(1) Built blanks (semifinished product) of the shell, the first-step output shaft, the second-step output shaft, and central input shaft. Based on given design parameters (Table 1), some main dimensions of these elements are drawn in an outline sketch. Then, by means of command "Rotate," the solid blank of these elements are created.

(2) Built a sweep path: by means of command "Insert base curve," the sweep curve can be created from tooth equations mentioned above.

(3) Applying a command "Pattern," above single element tooth is patterned into several teeth arrayed evenly and radially, and the $3 \mathrm{D}$ element model is constructed.

(4) In the environment of the UG software package, several "Assembly" commands are given, and above shell, the first-step output shaft, the second-step output shaft, and central input shaft are placed and assembled together, and the solid model for the drive system is created.

(5) 3D model of the drive system is imported into the software ANSYS. After imported into the software ANSYS, assembly relation in UG for $3 \mathrm{D}$ model of the drive does not exist. In the environment of the ANSYS software package, 3D models of all the volumes need to be reassembled. Here, the volumes are reassembled by defining contact elements. Between teeth of the elements, surface contacts are defined.

In this investigation, FEM analysis package, ANSYS, is used to calculate natural frequency and vibrating mode of the drive system. FEM models and mesh-dividing patterns for mode analysis of the drive are shown in Figure 2. Besides this, the contact units should be given between teeth of the elements.

In FEM analysis package, ANSYS, the mode analysis model is used. The mode number extracted is 20 . In operation of the drive, the shell is fixed, and central input shaft and the first- and second-step output shafts rotate. Hence, all the freedom degrees of the shell are removed, and other elements are given bearing constraint. Here, movable teeth, the first-step output shaft, the second-step output shaft, and central input shaft are made of steel. In this analysis, Modulus of elasticity of steel is $206 \mathrm{GPa}$, Poisson's ratio is 0.3 , and material density is $7850 \mathrm{~kg} / \mathrm{m}^{3}$.

\section{Natural Frequencies and Vibration Modes of the Drive System}

3.1. Classification of the Modes. The first twenty natural frequencies are analyzed, and the frequencies are listed in Tables 2 and 3. The twenty natural frequencies and the vibration modes can be classified as follows:
TABLE 1: Main parameters for the two-step sine movable tooth drive.

\begin{tabular}{lc}
\hline Speed ratio $i=i_{1} \cdot i_{2}$ & $6 \times 6$ \\
Motion radius of the sine ball track $R(\mathrm{~mm})$ & 29.5 \\
Ball radius $r(\mathrm{~mm})$ & 4.0 \\
Track radius $r^{\prime}(\mathrm{mm})$ & 4.4 \\
Track amplitude $A(\mathrm{~mm})$ & 3.6 \\
Period number of track $Z_{1}$ & 1 \\
Period number of track $Z_{2}$ & 1 \\
Period number of track $Z_{i}(i=3,4)$ & 5 \\
\hline
\end{tabular}

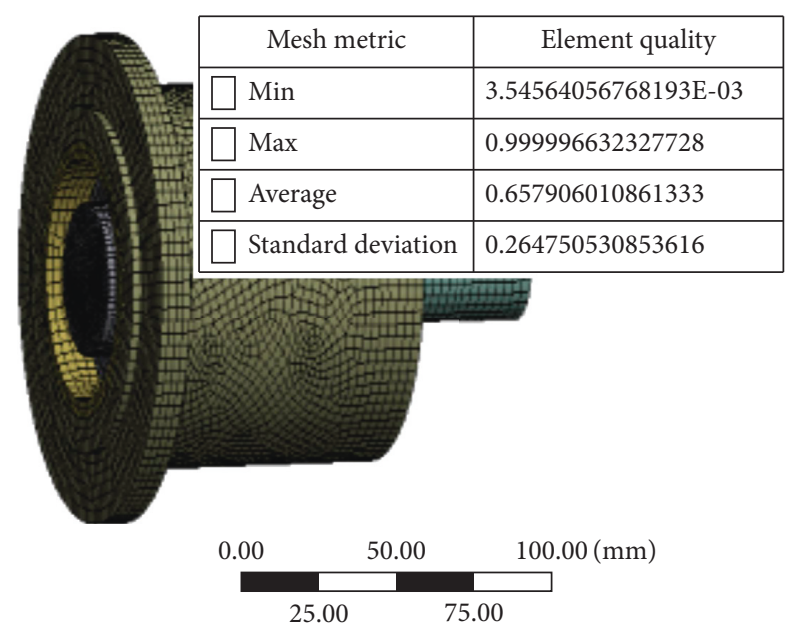

Figure 2: FEM model and mesh division of the drive system.

TABle 2: Natural frequencies and vibrating modes of the drive system.

\begin{tabular}{lcc}
\hline Order & $f(\mathrm{~Hz})$ & Vibrating modes \\
\hline 1 & 5359.8 & Total system vibration mode \\
2 & 7233.8 & Single-element vibration mode \\
3 & 7238.1 & Single-element vibration mode \\
4 & 7830.8 & Double-element vibration mode \\
5 & 8421.0 & Total system vibration mode \\
6 & 9028.3 & Double-element vibration mode \\
7 & 9159.2 & Four-element vibration mode \\
8 & 9463.4 & Four-element vibration mode \\
9 & 9661.2 & Three-element vibration mode \\
10 & 10316 & Four-element vibration mode \\
11 & 10867 & Three-element vibration mode \\
12 & 11268 & Double-element vibration mode \\
13 & 12801 & Double-element vibration mode \\
14 & 13608 & Double-element vibration mode \\
15 & 14532 & Double-element vibration mode \\
16 & 15033 & Three-element vibration mode \\
17 & 15498 & Three-element vibration mode \\
18 & 16157 & Three-element vibration mode \\
19 & 16550 & Three-element vibration mode \\
20 & 17130 & Double-element vibration mode \\
\hline
\end{tabular}

(1) Class one: the first and fifth natural frequencies. For these modes, vibrations occur in all elements. This mode is called as the total system vibration mode. All of the elements in the drive system vibrate simultaneously. The vibrations include bending vibrations 
TABLE 3: Types of the vibration modes of the drive system.

\begin{tabular}{lc}
\hline Types & modes \\
\hline Total system vibration & 1,5 \\
Single-element vibration & 2,3 \\
Double-element vibration & $4,6,12,13,14,15,20$ \\
Three-element vibration & $9,11,16,17.18,19$ \\
Four-element vibration & $7,8,10$ \\
\hline
\end{tabular}

of the guide beams in the first- and second-step output shafts, the bending vibration of the central input shaft, and the vibration of the first- and second-step movable teeth (Figure 3).

(2) Class two: the second-order and third-order natural frequencies. For these two types of the natural frequencies, vibration only occurs for one element. This mode is called the single-element vibration mode. Here, the second-order and third-order frequencies correspond to the bending vibration of the secondstep output shaft (Figure 4).

(3) Class three: orders 4, 6, 12, 13, 14, 15, and 20 of the natural frequencies. In this mode, vibrations occur for two elements (Figure 5). This mode is called the double-element vibration mode. In this mode, orders 4,14 , and 20 correspond to the vibrations of the output shaft and the second-step movable teeth, orders 6 and 12 correspond to vibrations of the firstand second-step output shafts, and orders 13 and 15 correspond to vibrations of the output shaft and the first-step movable teeth.

(4) Class four: orders 9, 11, 16, 17, 18, and 19 of the natural frequencies. In this mode, vibrations occur for three elements (Figure 6). This mode is called the three-element vibration mode. Here, orders 9, 16, 17, 18 , and 19 correspond to vibrations of the first-step output shaft, the second-step output shaft, and the second-step movable teeth. Order 11 corresponds to vibrations of the first-step output shaft, the secondstep output shaft, and the first-step movable teeth.

(5) Class five: orders 7, 8, and 10 of the natural frequencies. In this mode, vibrations occur for four elements. This mode is called the four-element vibration mode. Here, orders 7 and 8 correspond to vibrations of the first-step output shaft and movable teeth and the second-step output shaft and movable teeth. Order 10 corresponds to vibrations of the input shaft, the first-step output shaft, and the second-step output shaft and movable teeth (Figure 7).

Using the mode analysis model in FEM analysis package (ANSYS), natural frequencies, vibration shapes, and relative amplitudes between vibration displacements of the different positions and vibration shapes can be determined. For one vibration shape, the maximum relative vibration amplitude is found and given in Figure 8. It means that Figure 8 gives comparison of the maximum relative vibration amplitudes for different elements and different vibration modes. The relative vibration amplitudes of the main elements for the drive corresponding to the first 20 order modes are shown in Figure 8.
The vibration amplitudes of the second-step output shaft are the largest for most of the vibration modes. For the order 1 , the vibration amplitude of the input shaft is larger than that of the second-step output shaft. For the orders 10, 11, 13 , and 15, the vibration amplitudes of the first-step output shaft are larger than that of the second-step output shaft.

The vibration amplitudes of the second-step movable teeth are larger than those of the first-step output shaft for the orders $9,14,16$, and 20 . The vibration amplitudes of the second-step movable teeth are smaller than those of the first-step movable teeth for the orders $1,5,6,7,10,11,12,13$, and 15 .

As a whole, the vibration amplitudes of the first- and second-step output shafts are the larger than those of other elements, and the vibration amplitude of the second-step output shaft is the largest. It is caused by the weaker support stiffness of the second-step output shaft. The future work should be focused on improving design of the drive system to increase support stiffness of the second-step output shaft.

3.2. Effects of the Sine Track Amplitude. Here, we investigated effects of the sine track amplitude $A$ on the first 20 order natural frequencies and vibration amplitudes for the drive system (the track amplitude $A$ is taken to be $3.0 \mathrm{~mm}, 3.6 \mathrm{~mm}$, and $4.2 \mathrm{~mm}$, (Figure 9 and Table 4)).

The track amplitude $A$ has effects on the natural frequencies for the drive system. For mode 1, the natural frequency of the drive system increases with track amplitude $A$. When track amplitude $A$ changes from $3.0 \mathrm{~mm}$ to $4.2 \mathrm{~mm}$, the natural frequency increases by about $4.4 \%$.

For modes 2, 3, 4, 5, 8, 9, 19, and 20, the natural frequencies of the drive system first decrease and then increase with track amplitude $A$. When track amplitude $A$ changes from $3.0 \mathrm{~mm}$ to $4.2 \mathrm{~mm}$, the natural frequency is the smallest at $A=3.6 \mathrm{~mm}$. For mode 8 , the natural frequency at $A=$ $3.6 \mathrm{~mm}$ is $6.8 \%$ smaller than that at $A=3.0 \mathrm{~mm}$.

For modes $6,7,10,11,12,13$, and 14 , the natural frequencies of the drive system decrease with track amplitude $A$. When track amplitude $A$ changes from $3.0 \mathrm{~mm}$ to $4.2 \mathrm{~mm}$, the natural frequency of mode 14 decreases by $9.4 \%$.

For modes 15, 16, 17, and 18, the natural frequencies of the drive system first increase and then decrease with track amplitude $A$. When track amplitude $A$ changes from $3.0 \mathrm{~mm}$ to $4.2 \mathrm{~mm}$, the natural frequency is the largest at $A=3.6 \mathrm{~mm}$. For mode 15, the natural frequency at $A=3.6 \mathrm{~mm}$ is $8.1 \%$ larger than that at $A=4.2 \mathrm{~mm}$.

The effects of the track amplitude $A$ on the vibration amplitudes of the elements of the drive system are as follows:

(1) For modes 1, 2, 3, 17, and 20, the track amplitude $A$ has little effect on the vibration amplitudes of the first-step output shaft. For modes 4, 5, 16, and 18, the vibration amplitudes of the first-step output shaft are influenced significantly by the track amplitude $A$; at $A=3.6 \mathrm{~mm}$, the vibration amplitude is the smallest. Because the track amplitude $A$ is not equal to $3.6 \mathrm{~mm}$, the vibration amplitude increases significantly; for mode 5 , the vibration amplitude at $A=$ $3.6 \mathrm{~mm}$ is about half that of the vibration amplitudes at $A=3.0 \mathrm{~mm}$ or $4.2 \mathrm{~mm}$. For modes $7,10,12,13,15$, 


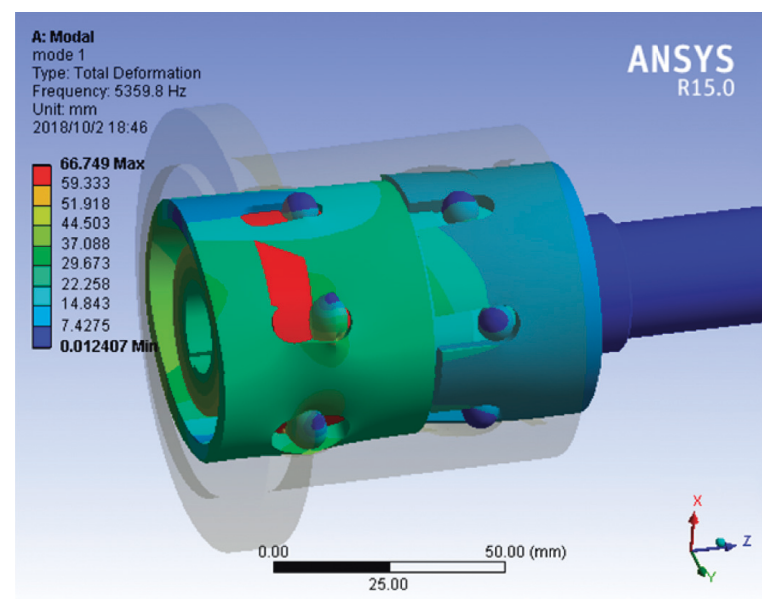

(a)

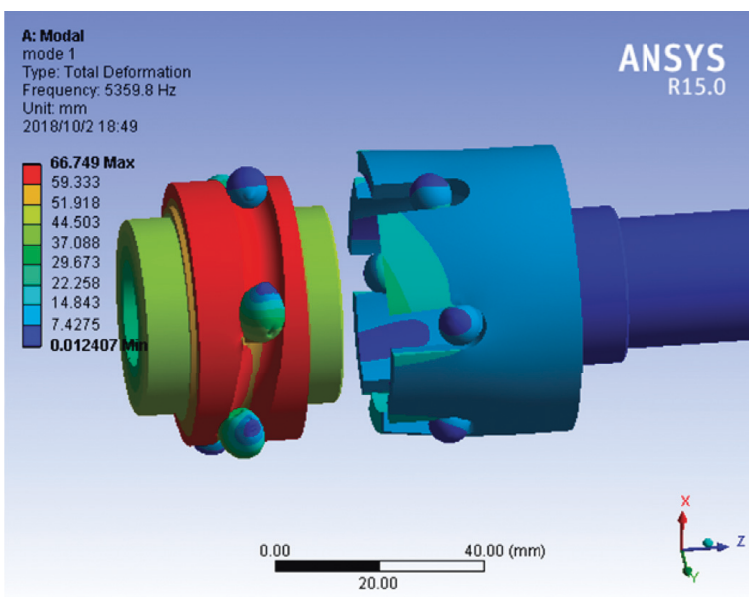

(b)

FIgURE 3: Total system vibration mode (mode 1).

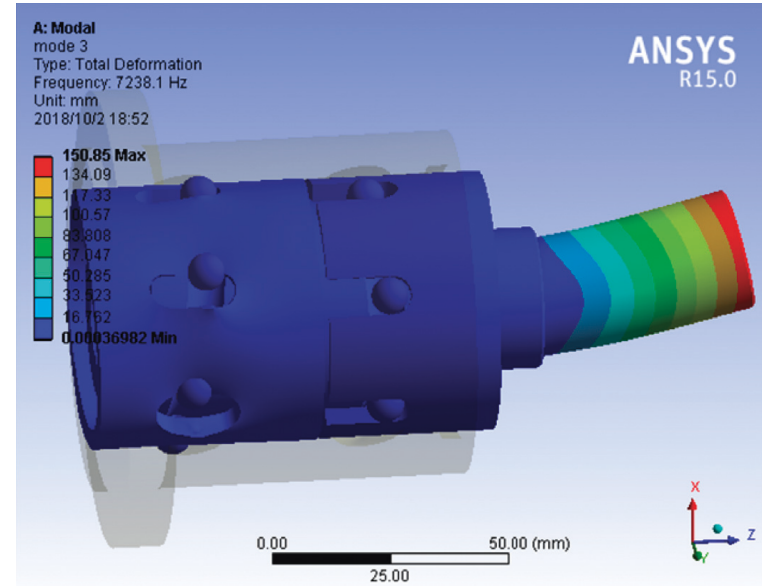

(a)

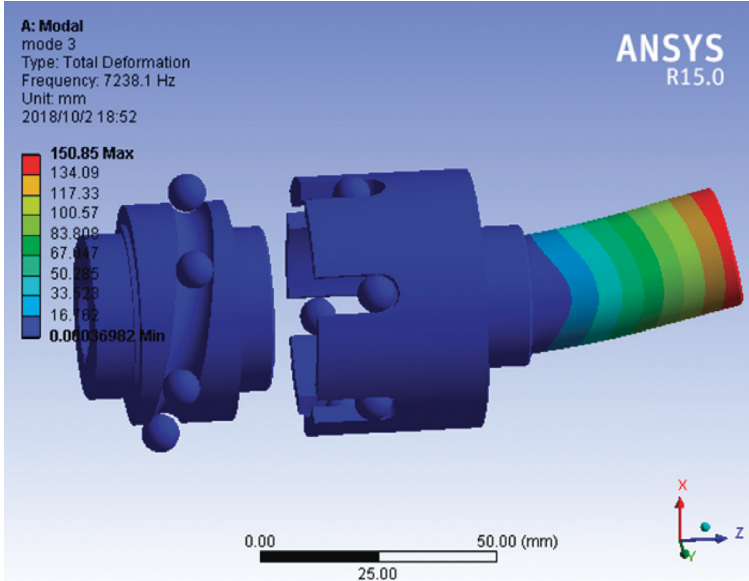

(b)

Figure 4: Single-element vibration mode (mode 3 ).

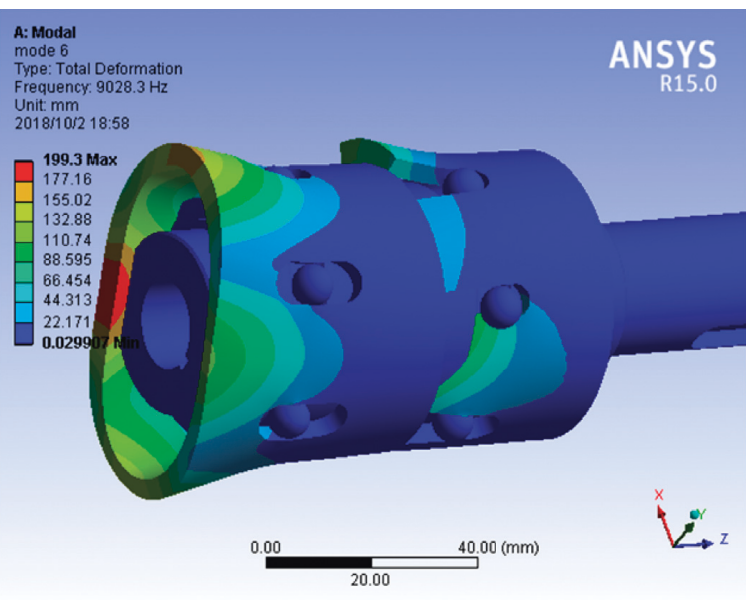

(a)

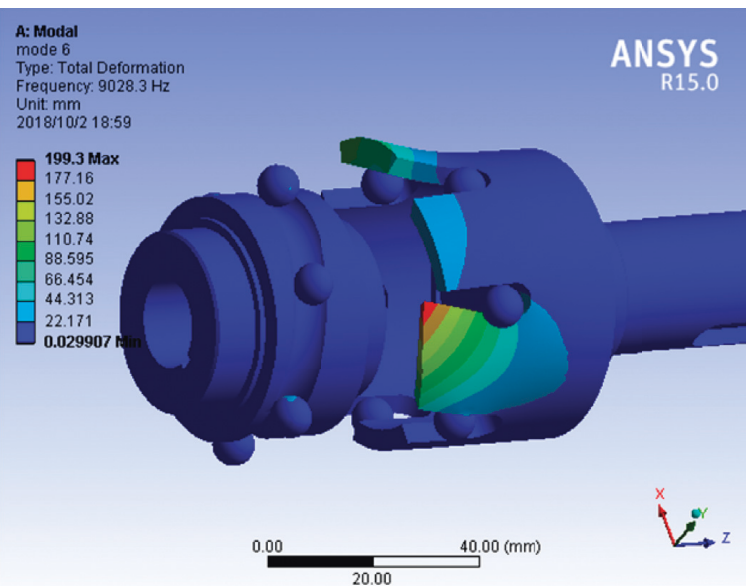

(b)

Figure 5: Double-element vibration mode (mode 6). 


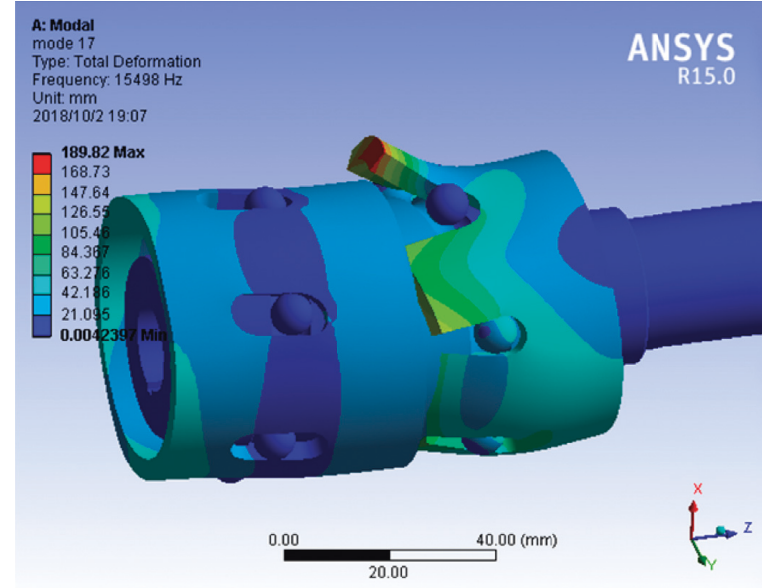

(a)

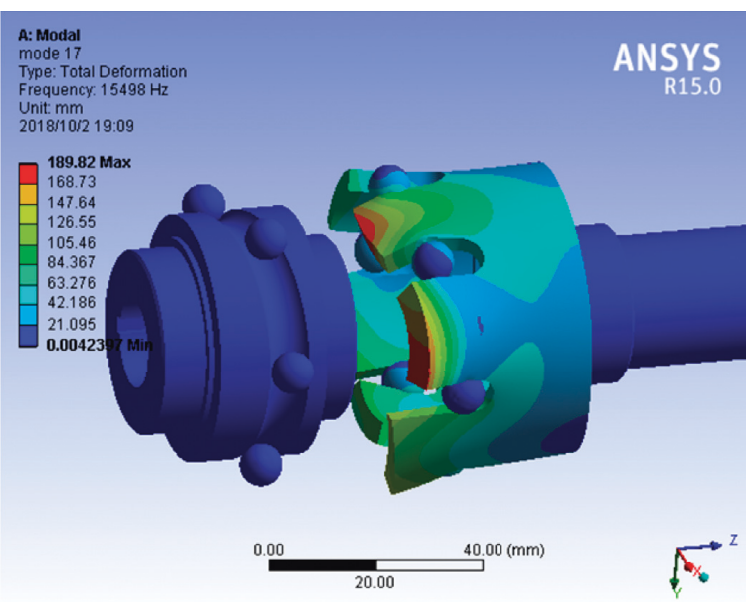

(b)

Figure 6: Three-element vibration mode (mode 17).

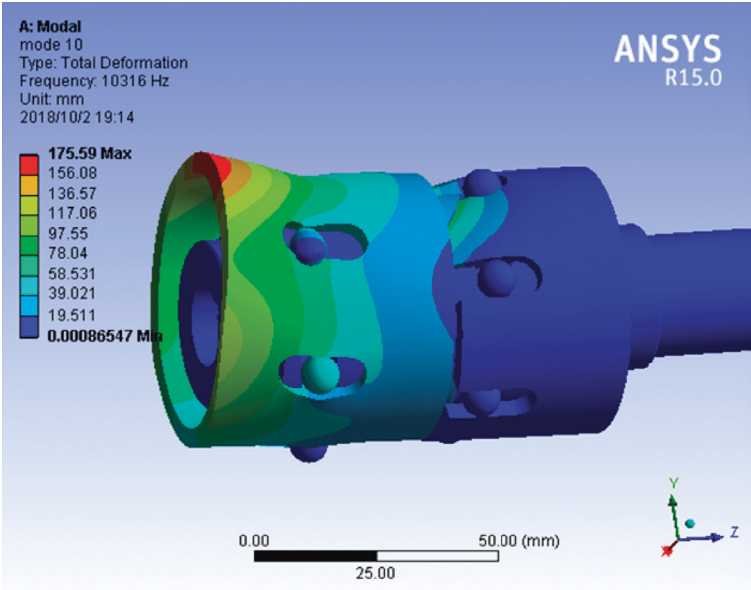

(a)

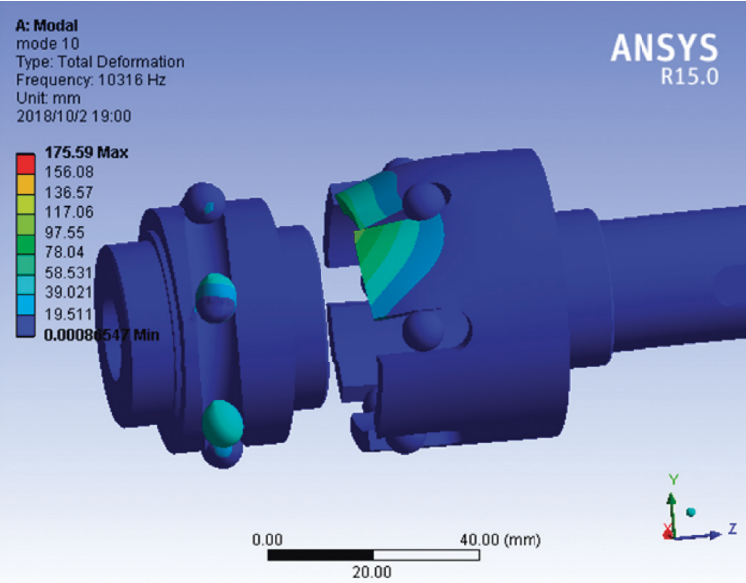

(b)

Figure 7: Four-element vibration mode (mode 10).

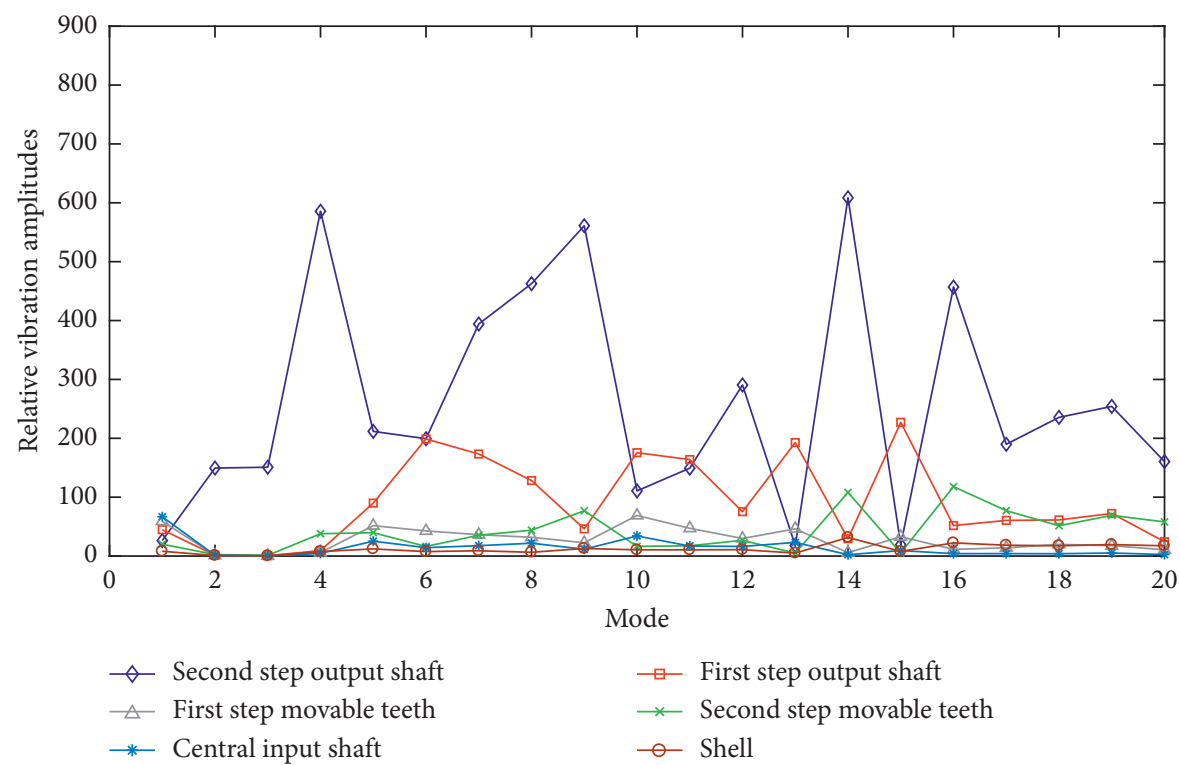

Figure 8: Relative vibration amplitudes of the main elements for the first 20 order modes. 

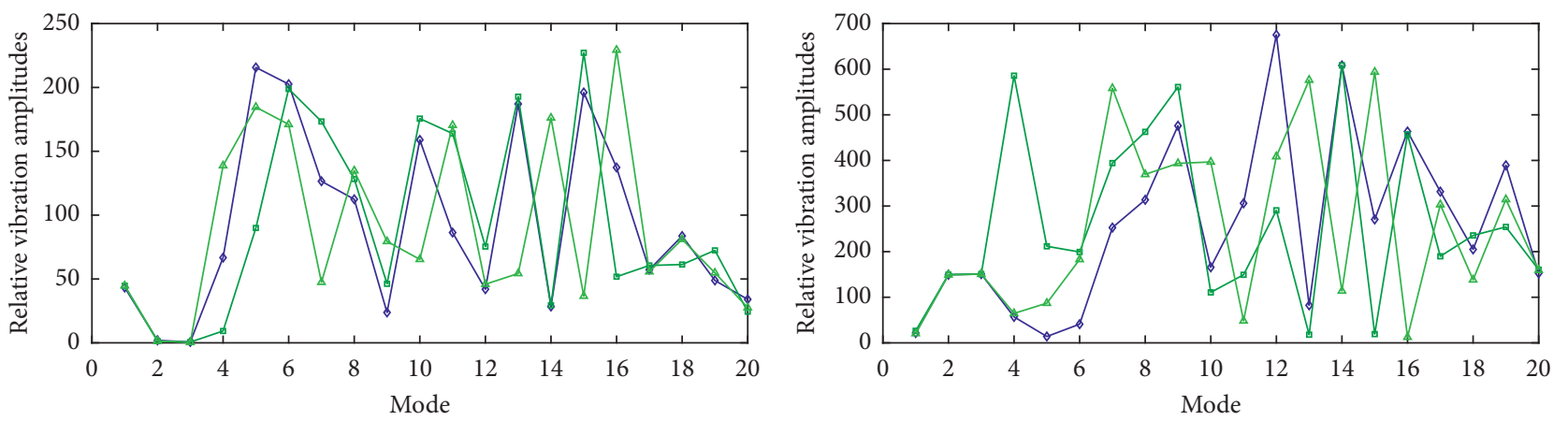

$\smile A=3.0$
$\neg \quad A=3.6$
$\triangle \quad A=4.2$

$\neg A=3.0$
$\square A=3.6$
$\triangle A=4.2$

(a)
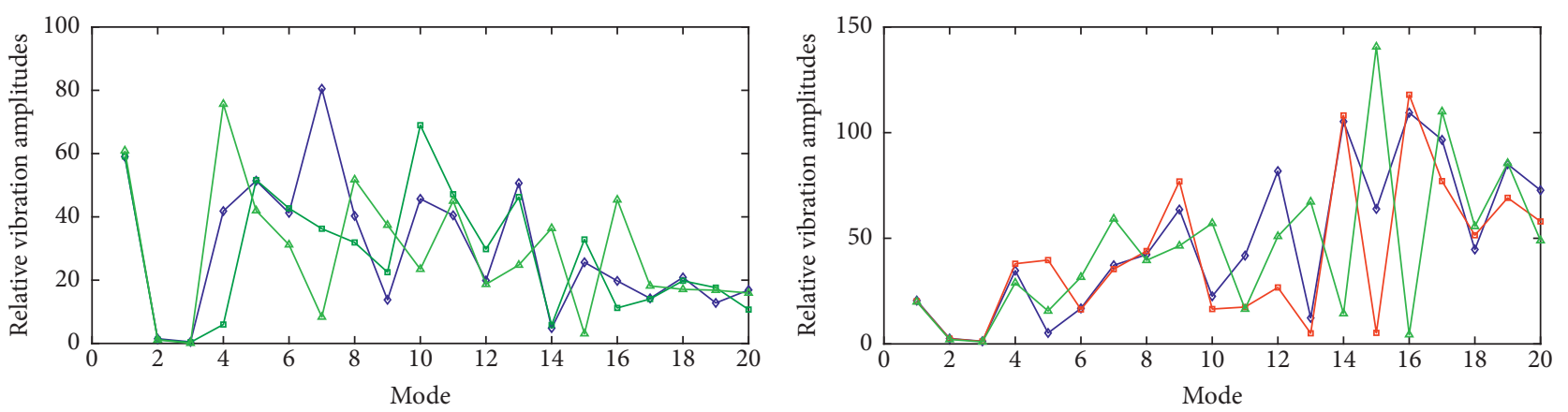

$\triangle A=3.0$
$\square A=3.6$
$\triangle A=4.2$

$\triangle A=3.0$
$\triangle A=3.6$
$\triangle \quad A=4.2$

(c)

(d)

FIGURE 9: Vibration amplitudes for several track amplitudes. (a) First-step output shaft; (b) second-step output shaft; (c) first-step movable teeth; (d) second-step movable teeth.

TABLE 4: Natural frequencies for several sine track amplitudes.

\begin{tabular}{lccccccc}
\hline Mode & 1 & 2 & 3 & 4 & 5 & 6 & 7 \\
\hline$A=3.0$ & 5263.4 & 7235.5 & 7240 & 8044.3 & 8918.6 & 9199.4 & 10003 \\
$A=3.6$ & 5359.8 & 7233.8 & 7238.1 & 7830.8 & 8241 & 9028.3 & 9159.2 \\
$A=4.2$ & 5494.6 & 7236.4 & 7241.4 & 8373.4 & 8844.5 & 9015 & 9068.5 \\
\hline Mode & 8 & 9 & 10 & 11 & 12 & 13 & 14 \\
\hline$A=3.0$ & 10158 & 10298 & 10682 & 10928 & 12254 & 12839 & 13809 \\
$A=3.6$ & 9463.4 & 9661.2 & 10316 & 10867 & 11268 & 12801 & 13608 \\
$A=4.2$ & 9580 & 9909.1 & 9978.3 & 10555 & 11163 & 12084 & 12506 \\
\hline Mode & 15 & 16 & 17 & 18 & 19 & 20 & \\
\hline$A=3.0$ & 14439 & 14472 & 15411 & 16071 & 16795 & 17188 & \\
$A=3.6$ & 14532 & 15033 & 15498 & 16157 & 16550 & 17130 & \\
$A=4.2$ & 13358 & 14285 & 15418 & 16014 & 16665 & 17411 & \\
\hline
\end{tabular}

and 19, the vibration amplitudes are influenced significantly by the track amplitude $A$ as well. At $A=$ $3.6 \mathrm{~mm}$, the vibration amplitude is largest because the track amplitude $A$ is not equal to $3.6 \mathrm{~mm}$, and the vibration amplitude is decreased significantly. For mode 7 , the vibration amplitude at $A=3.6 \mathrm{~mm}$ is about 1.4 times that of the vibration amplitude at $A=$ $3.0 \mathrm{~mm}$ and 3.7 times that of the vibration amplitude at $A=4.2 \mathrm{~mm}$. For mode 9, the vibration amplitude increases with the track amplitude $A$. For mode 6,10 , and 13 , the vibration amplitudes do not change when the track amplitude $A$ changes from $3.0 \mathrm{~mm}$ to $3.6 \mathrm{~mm}$; however, as the amplitude $A$ changes from $3.6 \mathrm{~mm}$ to $4.2 \mathrm{~mm}$, the vibration amplitude decreases. For modes 8 and 11, the vibration amplitudes increase when the track amplitude $A$ increases from $3.0 \mathrm{~mm}$ to $3.6 \mathrm{~mm}$; the vibration amplitudes do not change when the track amplitude $A$ increases from $3.6 \mathrm{~mm}$ to $4.2 \mathrm{~mm}$. For mode 14 , the vibration amplitudes do not change when the track amplitude $A$ increases from $3.0 \mathrm{~mm}$ to $3.6 \mathrm{~mm}$ but it increases significantly when the track amplitude $A$ increases from $3.6 \mathrm{~mm}$ to $4.2 \mathrm{~mm}$.

(2) The track amplitude $A$ has similar effects on the vibration amplitudes of the second-step output shaft. For modes 1, 2, 3, and 20, the track amplitude $A$ has little effect on the vibration amplitudes of the second-step output shaft. For modes 4, 5, 8, and 9, the vibration amplitudes are largest at $A=3.6 \mathrm{~mm}$. For modes $10,12,13,15,17$, and 19 , the vibration amplitudes are smallest at $A=3.6 \mathrm{~mm}$. For mode 7 , the vibration amplitude increases with the track 
amplitude $A$. For mode 6 , the vibration amplitude increases when the track amplitude $A$ increases from $3.0 \mathrm{~mm}$ to $3.6 \mathrm{~mm}$; the vibration amplitude does not change when the track amplitude $A$ increases from $3.6 \mathrm{~mm}$ to $4.2 \mathrm{~mm}$. For mode 11, the vibration amplitude decreases with the track amplitude $A$. For modes 14,16 , and 18 , the vibration amplitude does not change when the track amplitude $A$ increases from $3.0 \mathrm{~mm}$ to $3.6 \mathrm{~mm}$, and the vibration amplitude decreases when the track amplitude $A$ increases from $3.6 \mathrm{~mm}$ to $4.2 \mathrm{~mm}$.

(3) For modes 1, 2, 3, 11, 17, 18, 19, and 20, the track amplitude $A$ has little effect on the vibration amplitudes of the first-step movable teeth. For modes 10, 12, and 15, the vibration amplitudes of the first-step movable teeth are largest at $A=3.6 \mathrm{~mm}$. For modes 4,8 , and 16 , the vibration amplitudes are smallest at $A=3.6 \mathrm{~mm}$. For mode 9, the vibration amplitude increases with the track amplitude $A$. For mode 7 , the vibration amplitude decreases with the track amplitude $A$. For mode 14, the vibration amplitude does not change when the track amplitude $A$ increases from $3.0 \mathrm{~mm}$ to $3.6 \mathrm{~mm}$, and the vibration amplitude increases when the track amplitude $A$ increases from $3.6 \mathrm{~mm}$ to $4.2 \mathrm{~mm}$. For modes 5,6 , and 13 , the vibration amplitude does not change when the track amplitude $A$ increases from $3.0 \mathrm{~mm}$ to $3.6 \mathrm{~mm}$, and the vibration amplitude decreases when the track amplitude $A$ increases from $3.6 \mathrm{~mm}$ to $4.2 \mathrm{~mm}$.

(4) For modes 1, 2, 3, 4, 8, and 18, the track amplitude $A$ has little effect on the vibration amplitudes of the second-step movable teeth. For modes 5 and 9, the vibration amplitudes of the second-step movable teeth are largest at $A=3.6 \mathrm{~mm}$. For modes $12,15,17$, and 19 , the vibration amplitudes are smallest at $A=$ $3.6 \mathrm{~mm}$. For mode 20 , the vibration amplitude decreases with the track amplitude $A$. For mode $6,7,10$, and 13 , the vibration amplitude does not change when the track amplitude $A$ increases from $3.0 \mathrm{~mm}$ to $3.6 \mathrm{~mm}$, and the vibration amplitude increases when the track amplitude $A$ increases from $3.6 \mathrm{~mm}$ to $4.2 \mathrm{~mm}$. For mode 11, the vibration amplitude decreases when the track amplitude $A$ increases from $3.0 \mathrm{~mm}$ to $3.6 \mathrm{~mm}$, and the vibration amplitude does not change when the track amplitude $A$ increases from $3.6 \mathrm{~mm}$ to $4.2 \mathrm{~mm}$. For modes 14 and 16, the vibration amplitude does not change when the track amplitude $A$ increases from $3.0 \mathrm{~mm}$ to $3.6 \mathrm{~mm}$, and the vibration amplitude decreases when the track amplitude $A$ increases from $3.6 \mathrm{~mm}$ to $4.2 \mathrm{~mm}$.

3.3. Effects of the Movable Tooth Radius, Rotation Radius, and Movable Tooth Number. Besides, we also investigated effects of the movable tooth radius $r$, its rotation radius $R$, and movable tooth number on the first 20 order natural frequencies and vibration amplitudes for the drive system. Here, the movable tooth radius $r$ is taken to be $3 \mathrm{~mm}, 4 \mathrm{~mm}$, and $5 \mathrm{~mm}$; the radius $R$ is taken to be $23.5 \mathrm{~mm}, 25.5 \mathrm{~mm}$, and $27.5 \mathrm{~mm}$; the tooth number $z$ is taken to be $5 \times 5,6 \times 6$, and $7 \times 7$. To limit length of the paper, only effects of these factors on the vibration amplitudes of the second-step output shaft are shown (Figures 10 and 11). Figures 10 and 11 show the following:

(1) Movable tooth radius $r$ has effects on the natural frequencies for the drive system. For the first four orders of the modes, the natural frequencies of the drive system first increase and then decrease with radius $r$. When radius $r$ increases from $3 \mathrm{~mm}$ to $5 \mathrm{~mm}$, the natural frequency is largest at $r=4 \mathrm{~mm}$. For mode 1, the natural frequency at $r=4 \mathrm{~mm}$ is $14.7 \%$ larger than that at $r=3 \mathrm{~mm}$. For other modes, the natural frequency increases with radius $r$. As radius $r$ increases from $3 \mathrm{~mm}$ to $5 \mathrm{~mm}$, the natural frequency of the fifth order mode increases by $33.3 \%$. It shows that the radius $r$ have more obvious effects on the natural frequencies of the drive system than the track amplitude $A$.

(2) For the first three orders of the modes, the natural frequencies of the drive system nearly do not change with radius $R$. The relative difference between the natural frequencies for different radius $R$ is about $0.1 \%$. After mode 4 , the natural frequencies of the drive system decrease with radius $R$. For mode 12, the relative difference between the natural frequencies for different radius $R$ gets to the maximum (15.8\%). After mode 17 , the relative difference between the natural frequencies for different radius $R$ reduces gradually. For mode 20, the relative difference between the natural frequencies reduces to be $2.4 \%$.

(3) For the modes 2, 3, 6, 11, 17, 18, 19, and 20, the natural frequency of the drive system does not change with the number of the movable teeth. For mode 2, the relative error between the natural frequencies for different tooth number is about $1.8 \%$. For the modes $1,5,6,7,11$, and 20 , the natural frequency of the drive system increases with number of the movable teeth. For mode 7 , the relative error between the natural frequencies for different tooth number gets to about $12.3 \%$. For the mode 4 , the natural frequency of the drive system decreases with number of the movable teeth. Here, the relative error between the natural frequencies for different tooth number is about $2 \%$. For the modes $8,9,10,12,13,18$, and 19 , the natural frequencies first decrease and then increase with tooth number. For mode 9, the relative error between the natural frequencies is about $8.4 \%$. For the modes 2,3 , 15,16 , and 17 , the natural frequencies of the drive system first increase and then decrease with tooth number. For mode 15, the relative error between the natural frequencies is about $7.3 \%$.

(4) The movable tooth radius $r$ has obvious effects on the vibration amplitudes of the second-step output shaft except mode 1. For modes 6, 18, and 19, the vibration amplitude of the second-step output shaft decreases with the radius $r$. For modes 2, 3, and 12, 


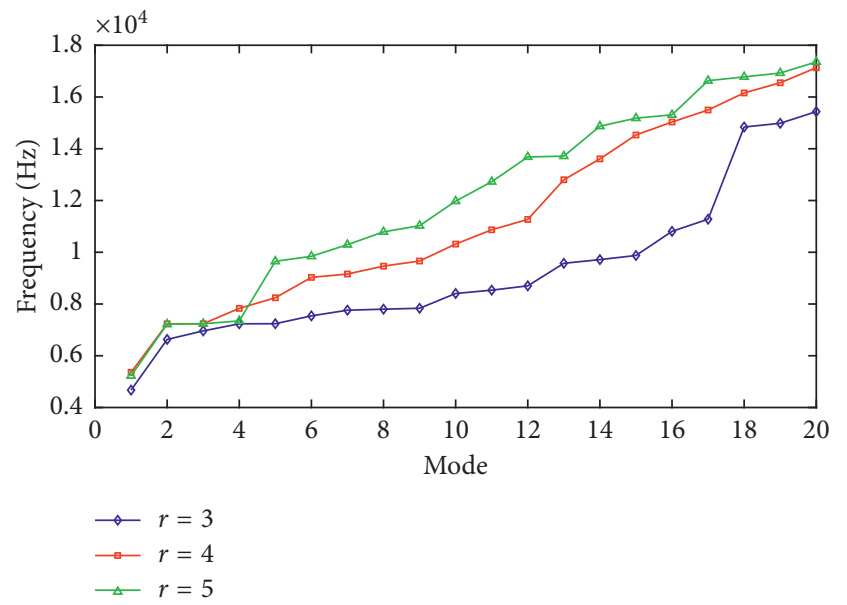

(a)

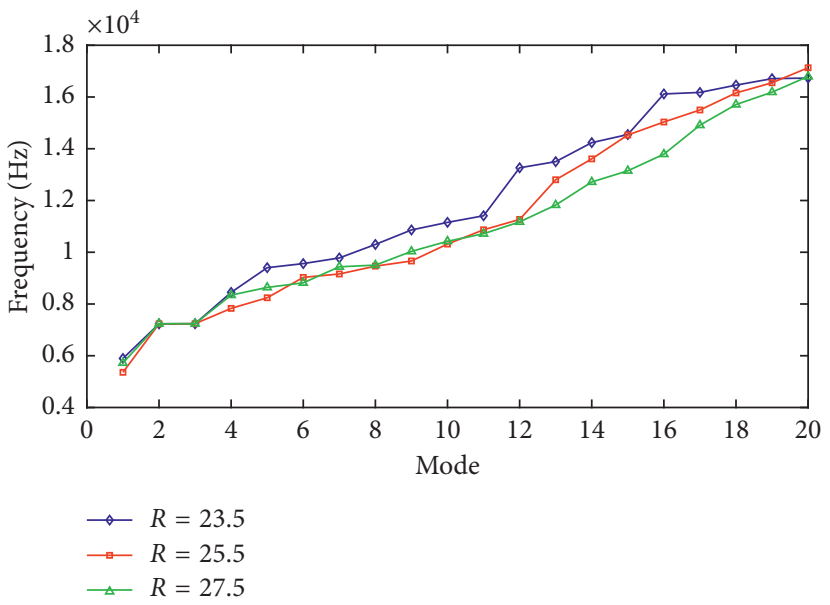

(b)

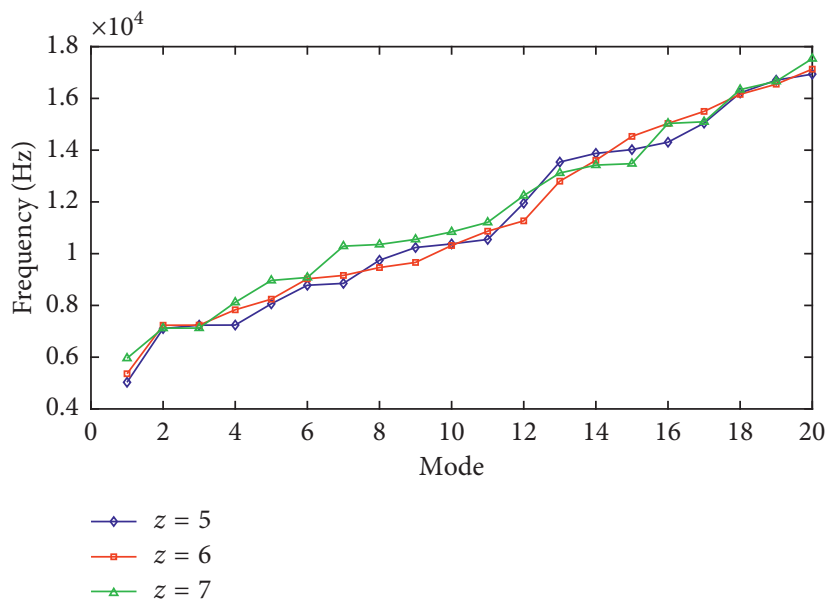

(c)

FIgURE 10: Natural frequencies as functions of the system parameters.

the vibration amplitude decreases when the radius $r$ increases from $3 \mathrm{~mm}$ to $4 \mathrm{~mm}$, but it does not change when the radius increases from $4 \mathrm{~mm}$ to $5 \mathrm{~mm}$. For modes $4,5,7,8,9,14,16$, and 17 , the vibration amplitudes first increase and then decrease with the radius $r$. At $r=4 \mathrm{~mm}$, the vibration amplitude is largest. For modes 10, 11, and 20, the vibration amplitude first decreases and then increases with the radius $r$. At $r=4 \mathrm{~mm}$, the vibration amplitude is smallest. For modes 13 and 15, the vibration amplitude does not change when the radius increases from $3 \mathrm{~mm}$ to $5 \mathrm{~mm}$, but it increases when the radius $r$ increases from $4 \mathrm{~mm}$ to $5 \mathrm{~mm}$.

(5) For modes 1, 2, 3, 15, and 18, the radius $R$ has little effect on the vibration amplitudes of the second-step output shaft. For modes 4, 5, 8, and 9, the vibration amplitudes of the second-step output shaft first increase and then decrease with movable tooth radius $R$. For modes 6 and 12, the vibration amplitudes decrease with movable tooth radius $R$. For modes 7 , $14,16,19$, and 20 , the vibration amplitude increases when the radius $R$ increases from $23.5 \mathrm{~mm}$ to
$25.5 \mathrm{~mm}$, but it does not change when the radius $R$ increases from $25.5 \mathrm{~mm}$ to $27.5 \mathrm{~mm}$. For modes 10 , 11 , and 13, the vibration amplitude first decreases and then increases with the radius $R$. For mode 17, the vibration amplitude increases with the radius $R$.

(6) For modes 1, 3, 6, and 13, the tooth number $z$ has little effect on the vibration amplitudes of the second-step output shaft. For modes 2 and 17, the vibration amplitudes of the second-step output shaft first decrease and then do not change with movable tooth number $z$. For mode 5, the vibration amplitude decreases with movable tooth number $z$. For modes 4,6 , 8 , and 16 , the vibration amplitudes first increase and then drop with movable tooth number $z$. For modes 7 , 10 , and 14 , the vibration amplitudes increase with movable tooth number $z$. For modes 9 and 19, the vibration amplitudes first increase and then do not change. For modes $11,12,15$, and 18 , the vibration amplitudes first decrease and then increase with movable tooth number $z$. For mode 20, the vibration amplitude first does not change ( $z$ changes from 5 to 6 ) and then increases ( $z$ changes from 6 to 7 ). 


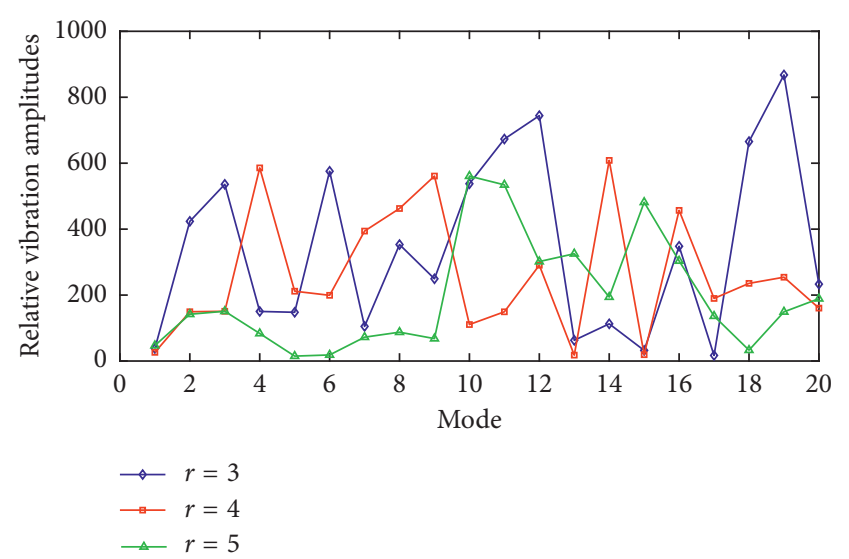

(a)

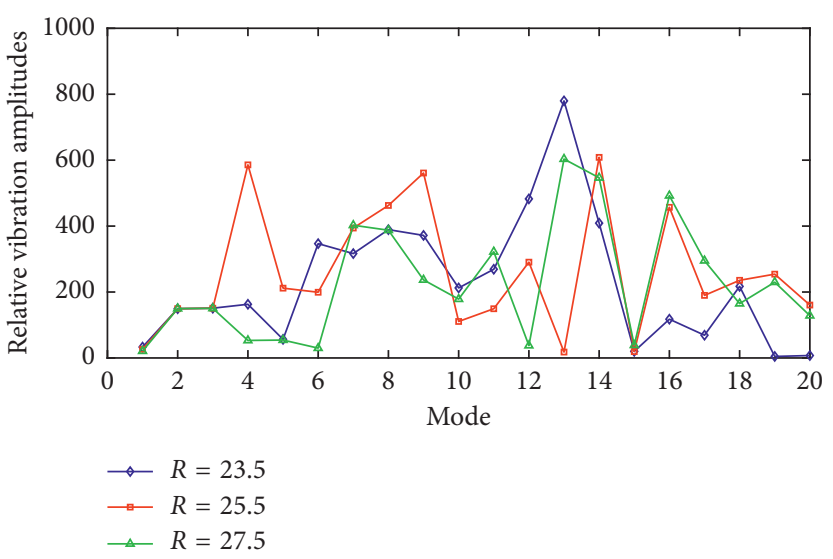

(b)

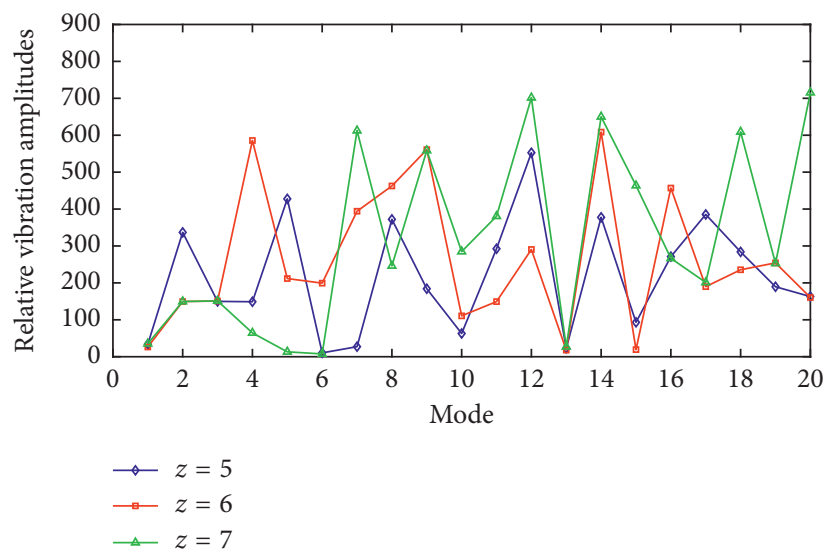

(c)

Figure 11: Vibration amplitudes of the second-step output shaft as functions of the system parameters.

In a word, the drive parameters have significant effects on the natural frequencies and vibration modes. By tuning these parameters, the natural frequencies or vibration amplitudes of the drive system can be changed.

For example, to increase natural frequency of the tenth order mode, the radius $r$ of the movable teeth should be taken to be a larger value, the rotation radius $R$ should be a smaller value, the sine track amplitude $A$ should be a larger value, and the movable tooth number $z$ should be a larger value.

To reduce vibration amplitude of the second-step output shaft for the tenth order mode, the radius $r$ of the movable teeth should be taken to be an optimum value, the rotation radius $R$ should be an optimum value, the sine track amplitude $A$ should be an optimum value, and the movable tooth number $z$ should be a smaller value.

\section{Conclusions}

In this study, 3D models of the main elements of a two-step sine movable tooth drive are developed. The FEM analysis package, ANSYS Workbench, is used to calculate the natural frequencies and vibration modes of the drive system. The following conclusions are drawn:
(1) The first twenty natural modes are classified into five families; these include the total system vibration mode, single-element vibration mode, two-element vibration mode, three-element vibration mode, and four-element vibration mode.

(2) In the total system vibration mode, vibrations occur for all elements. Only the second-step output shaft vibrates in the single-element vibration mode.

(3) The vibration amplitudes of the second-step output shaft are largest and are caused by the weak support stiffness of the second-step output shaft.

(4) By tuning the drive parameters, the natural frequencies and vibration amplitudes of the drive system can be changed significantly.

\section{Data Availability}

The data used in our manuscript can be obtained by FEM model with ANSYS software.

\section{Conflicts of Interest}

The authors declare that they have no conflicts of interest. 


\section{Acknowledgments}

This project was supported by the Hebei Province Natural

Science Foundation in China (no. E2017203021).

\section{References}

[1] S. Keith, "Subtractive and additive differential gear reduction system," US Patent US4338830A, 1982.

[2] I. Kenji, "Ball-rolling type torque transmission device," US Patent US5683323A, 1997.

[3] H. Terada, H. Makino, and K. Imase, "Fundamental analysis of cycloid ball reducer ( $1^{\text {st }}$ report): motion principle," Journal of the Japan Society for Precision Engineering, vol. 54, no. 11, pp. 2101-2106, 1988.

[4] H. Terada, H. Makino, and K. Imase, "Fundamental analysis of cycloid ball reducer ( $2^{\text {nd }}$ report): radius of curvature and pressure angle," Journal of the Japan Society for Precision Engineering, vol. 56, no. 4, pp. 751-756, 1990.

[5] H. Terada, H. Makino, and K. Imase, "Fundamental analysis of cycloid ball reducer ( $3^{\text {rd }}$ report): strength design," Journal of the Japan Society for Precision Engineering, vol. 61, no. 12, pp. 1705-1709, 1995.

[6] H. Terada, H. Makino, and K. Imase, "Fundamental analysis of cycloid ball reducer ( $4^{\text {th }}$ report): efficiency analysis and development of the Oldham's type output mechanism," Journal of the Japan Society for Precision Engineering, vol. 63, no. 6, pp. 834-838, 1997.

[7] G. Li, G. Yu, and Y. Sun, "Application of grey-relational theory in fault tree analysis of miniature sine oscillating tooth gear drive," Chinese Journal of Construction Machinery, vol. 4, pp. 127-132, 2006.

[8] H. Terada and K. Imase, "Fundamental analysis of a cycloid ball reducer $\left(5^{\text {th }}\right.$ report): development of a two stage type reduction mechanism," Journal of the Japan Society for Precision Engineering, vol. 75, no. 12, pp. 1418-1422, 2009.

[9] H. Terada, "The Development of gearless reducers with rolling balls," Journal of Mechanical Science and Technology, vol. 24, no. 1, pp. 189-195, 2010.

[10] S. Liang, B. Fu, and D. Wang, "Tooth profile synthesis and strength computation of swing movable teeth drives," Key Engineering Materials, vol. 474-476, pp. 162-167, 2011.

[11] A. Sapsalev, Optimizing Cyclic Gearless Electric Drives with a Reduced-Speed Section, Vol. 5-6, Allerton Press Inc., New York, NY, USA, 2012.

[12] W. Nam, J. Shin, and S. Oh, "Design of thin plate-type speed reducers using balls for robots," Journal of Mechanical Science and Technology, vol. 27, no. 2, pp. 519-524, 2013.

[13] S. Nishibe, S. Mitsufuji, and Y. Nishitani, "Eccentric oscillating reduction gear for joint drive of robot," JP Patent JP2014161952A, 2014.

[14] Y. Liang and L. Xu, "Free vibration for an electromagnetic harmonic movable tooth drive system," Open Mechanical Engineering Journal, vol. 9, no. 1, pp. 15-21, 2015.

[15] L. Xu and Y. Liang, "Torque for an electromagnetic harmonic movable tooth drive system," Mechanism and Machine Theory, vol. 98, pp. 190-198, 2016.

[16] L. Xu, W. Song, and R. Li, "Two-step sine movable tooth drive," Advances in Mechanical Engineering, vol. 9, no. 6, pp. 1-9, 2017. 


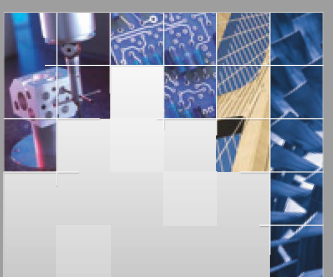

\section{Enfincering}
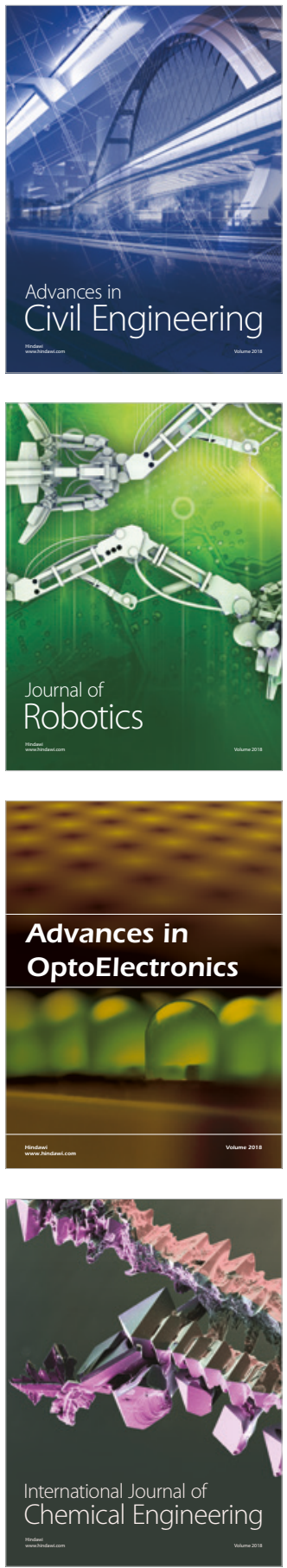

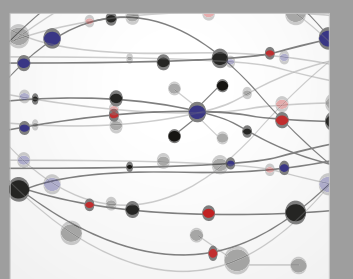

\section{Rotating \\ Machinery}

The Scientific World Journal

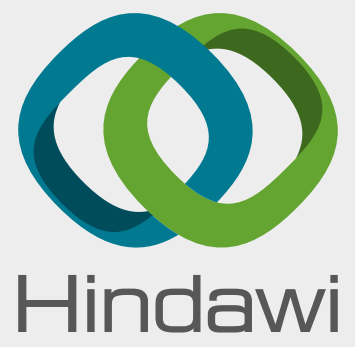

Submit your manuscripts at

www.hindawi.com
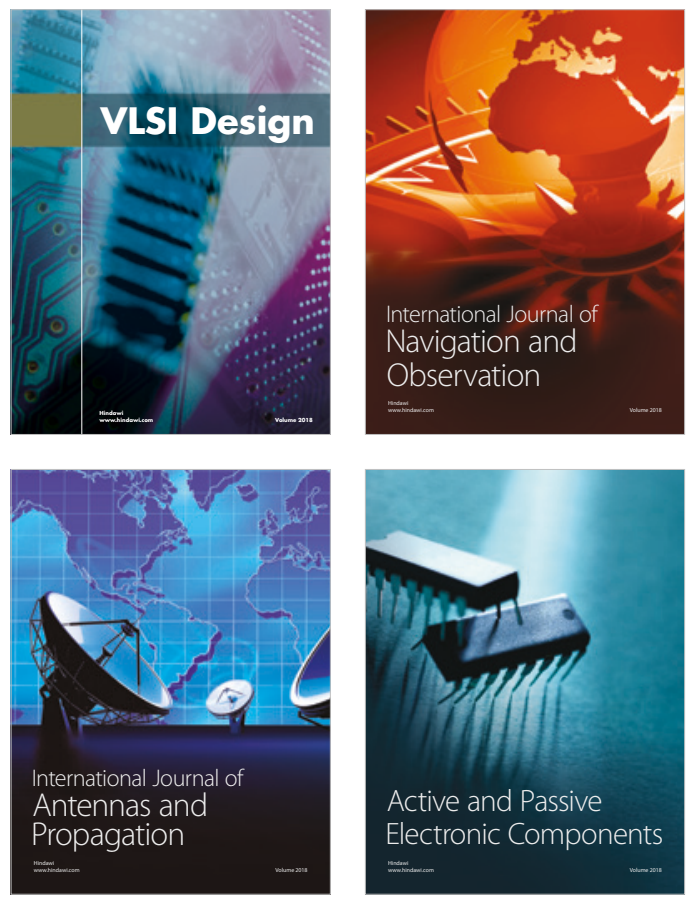
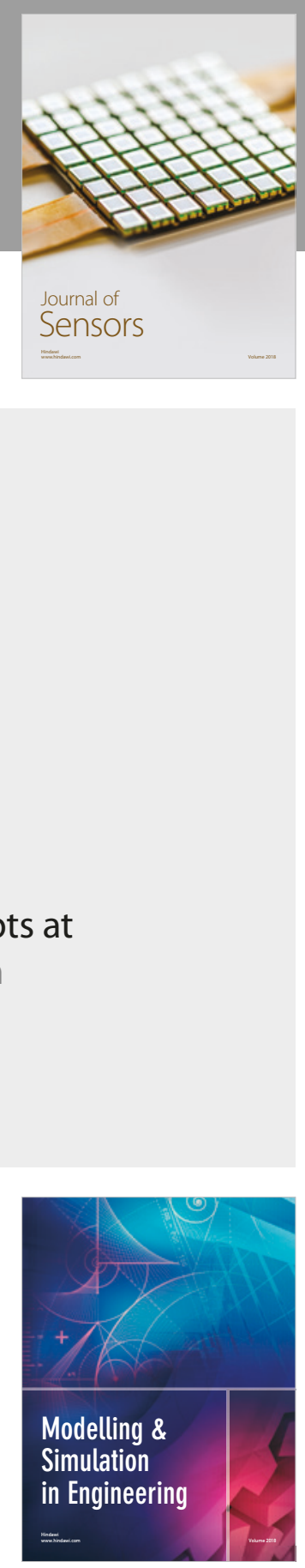

\section{Advances \\ Multimedia}
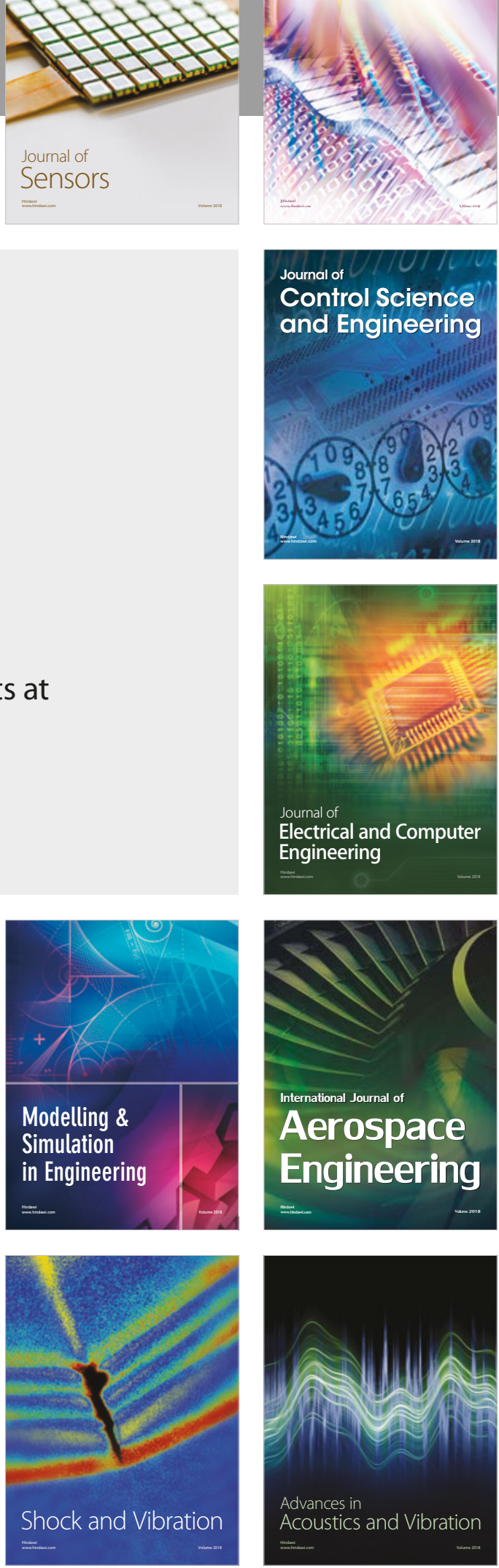